\title{
Study on Evaluating the EMI Filter for Electronic Communication Fans
}

\author{
Ching-Chun Chuang ${ }^{1, *}$, Chih-Chiang Hua ${ }^{2}$, Chung-Wen Hung², Chun-Jen Yao ${ }^{3}$ \\ ${ }^{1}$ Department of Computer Science and Information Engineering, National Formosa University, No. 63, Wunhua Rd., \\ Huwei Township, Yunlin 632, Taiwan (R.O.C) \\ ${ }^{2}$ Department of Electrical Engineering, National Yunlin University of Science and Technology, No. 123, University Rd., \\ Section 3, Douliu, Yunlin 64002, Taiwan (R.O.C) \\ ${ }^{3}$ Department of Electronics and Computer Engineering, National Taiwan University of Science and Technology, No. 43, Section 3, \\ Keelung Rd., Taipei City 106, Taiwan (R.O.C)
}

\section{ARTICLE INFO}

\section{Article History}

Received 30 October 2020 Accepted 14 September 2021

Keywords

Electronically commutated fan electromagnetic compatibility digital control strategy

\begin{abstract}
An electronically commutated fan has a complex digital control mode compared to the conventional alternating current fans. Since a serious electromagnetic compatibility situation occurs in the electronic commutation fan system, the filter circuit and mechanical design of a fan system are very important. A digital control strategy for a fan was designed to reduce the component of the electromagnetic interference filter, therefore the suppression of conducted and radiated electromagnetic interference will be achieved in the proposed fan system. Moreover, the proposed fan integrates the mechanical design to solve the problems of radiated electromagnetic interference. A single-phase Brushless DC Electric Motor (BLDC) driver is designed and constructed. Finally, the electromagnetic interference that occurred in the proposed fan is analyzed and the suppression strategy is provided. The experiment verification for the electronically commutated fan is presented.
\end{abstract}

(C) 2021 The Authors. Published by Atlantis Press International B.V.

This is an open access article distributed under the CC BY-NC 4.0 license (http://creativecommons.org/licenses/by-nc/4.0/).

\section{INTRODUCTION}

The electronic communication fan combines the frequency conversion function, and the power transistors for frequency modulation to achieve speed control. Because of the higher speed, the motor output efficiency is improved. The Single-Phase BLDC motor system is driven by an AC power supply. A DC motor is used for this system, so the friction loss is reduced. The advantages of $\mathrm{AC}$ and $\mathrm{DC}$ fans are combined to improve the efficiency and life of the electronic commutation fan. Figure 1 shows the circuit topology of a commercial electronic commutation fan. Several switch devices were switched at high speed, and the voltage and current are changed at the same time. The result not only causes more serious electromagnetic interference problems [1,2] but also affects the electromagnetic tolerance of the internal controller. Therefore, the production design has to be considered for passing relevant electromagnetic compatibility certification.

\section{EMI STANDARD FOR ELECTRONIC COMMUNICATION SYSTEM}

Generally speaking, the tests of electromagnetic compatibility are divided into two types: Electromagnetic Interference (EMI) and electromagnetic susceptibility $[3,4]$. The EMI testing refers to measure of the intensity of conductive interference and radiant interference while the electronics device is normally operated during the testing procedure. The purpose of electromagnetic interference

“Corresponding author.Email: austincc@nfu.edu.tw suppression design is to reduce the intensity of noise generated by the electronics device under testing, and it was not to affect other electronic products in the test environment. On the contrary, the purpose of electromagnetic tolerance is to prevent the device under test (DUT) from being interfered with by other electronic products in the environment during operations.

There are international standards for the electromagnetic interference law of electronic communication fans, which can refer to the European regulations EN 55011, the United States FCC PART 18, and the domestic CNS 13803. Among them, there are two different limit values of class A and B according to the type of this product, which is either commercial or residential households. However, the product analysis in this paper will be used in information products since Europe is the main market. So, the information products for European standards will be adopted. Class B electromagnetic interference standards in EN55022, EN55022, and EN55011 are the same as for Class B electromagnetic interference test standards.

\section{EMI SUPPRESSION AND ANALYSIS OF ELECTRONIC COMMUNICATION SYSTEM}

\subsection{Conduction EMI Measurement}

To measure the noise values of the live wire (Line, L) and the neutral wire (Neutral, N) after a connection of the 


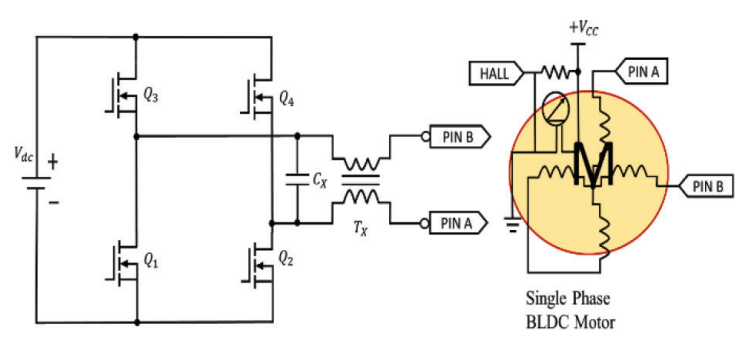

Figure 1 Single-phase BLDC motor driver schematic diagram.

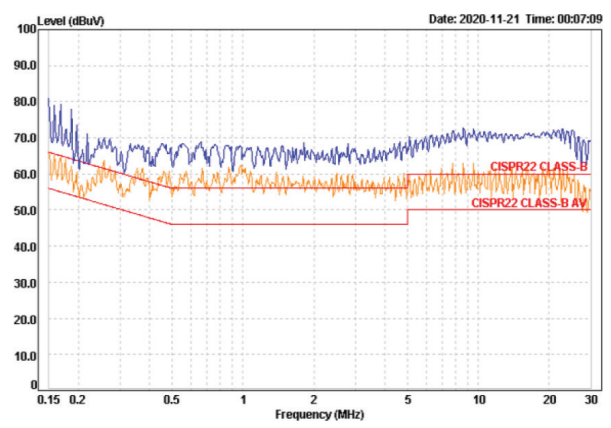

Figure 2 EMI testing of L phase conductivity.



Figure 3 EMI testing of $\mathrm{N}$ phase conductivity.

line impedance stabilization network (LISN). The measured results are shown in Figures 2 and 3. Observing the two figures, it can be seen that the test value without any filter and other countermeasures far exceeds the standard limit value.

\subsection{Radiation EMI Measurement}

According to the above section, the noise measurement of the EUT was received through the antenna under two different polarities, verti$\mathrm{cal}$ and polar. The actual test diagrams are shown in Figures 4 and 5. It can also be seen that the noise radiated through space is very serious.

\subsection{The Suppression Strategy for Conduction EMI and Radiation EMI}

\subsubsection{A strategy of conduction EMI}

Conducted EMI is mainly used to measure the noise transmitted by the power line through LISN, so the main suppression method is to add an EMI filter to the power line [5]. However, it can be seen that a multi-stage filter with grounding is required to have a wider suppression range from Figure 2. In this paper, the space of the DUT is limited, and there is no ground wire architecture. The input EMI filter architecture of the electronic commutation fan systems is show in Figure 6. The differential mode inductance is $100 \mu \mathrm{H}$, the $\mathrm{X}$ capacitor is $0.1 \mu \mathrm{F}$, and the common-mode inductance is $20 \mathrm{mH}$.

With the advantage of digital control, Spread Spectrum [6-9] is added to suppress the interference problem caused by the main operating frequency.

$$
\text { Attenuation }=10 \log \left(\frac{N \times \delta \times f_{c}}{f_{m}}\right)
$$

where $N$ is the harmonic number

$\delta$ is spread spectrum

$f_{c}$ is switching frequency

$f_{m}$ is frequency modulation

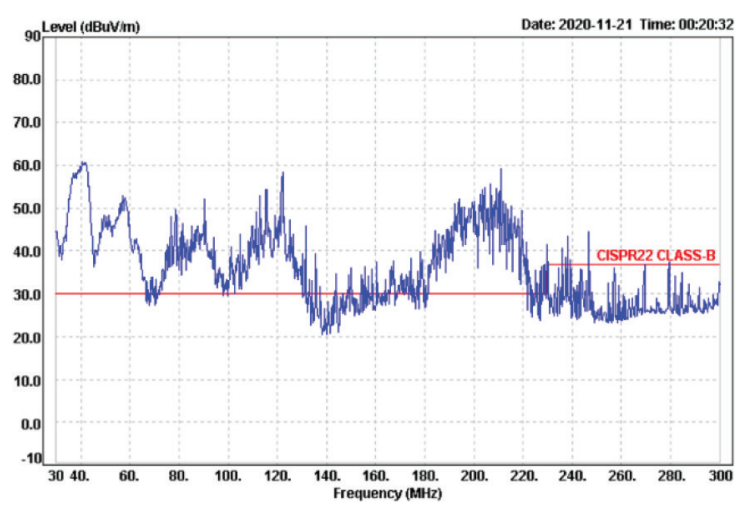

Figure 4 The vertical polarity test of radiation EMI.

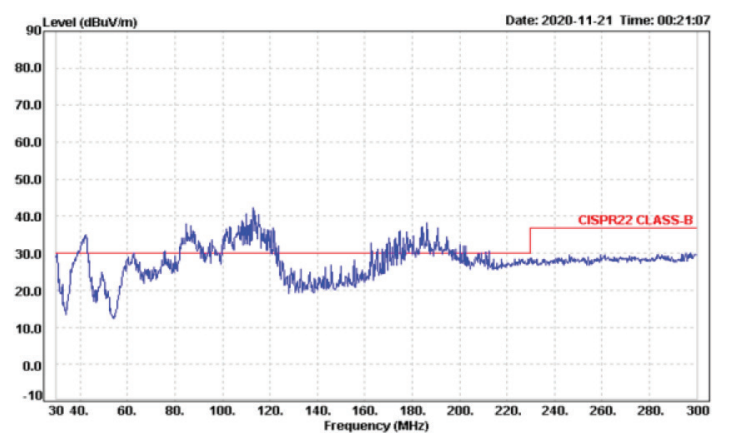

Figure 5 The horizontal polarity test of radiation EMI.

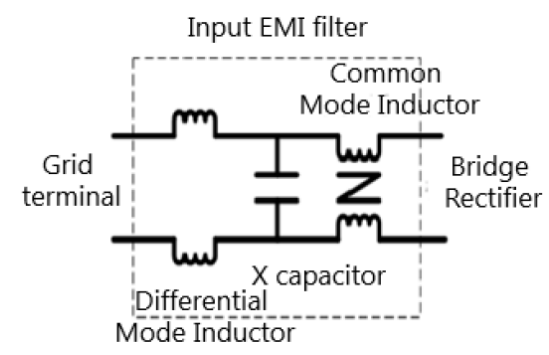

Figure 6 Input EMI filter structure. 
Figures 7 and 8 show the actual test patterns after adding the input EMI filter and other countermeasures to the EUT internal circuit.

\subsubsection{A strategy of radiation EMI}

To solve the radiation problem between the circuit output and the motor, an output EMI filter design is required for the electronic commutation fan systems. The common-mode inductance is $0.95 \mathrm{mH}$ and the $\mathrm{X}$ capacitor is $4700 \mathrm{pF}$. Both the useful safety certified components, as shown in Figure 9.

The proposed EUT has two types, namely plastic fan blades and metal fan blades. Among them, the series of metal fan blades have the most serious radiated EMI problem. The noise generated by the drive motor will provide a path to the metal fan blade through the metal shaft, which results in a serious antenna effect. Therefore, an insulating part will be added to the mechanism part, as shown in Figure 10, which not only saves the cost of motor manufacturing but also solves the problem of radiated EMI. Figures 11 and 12 show the actual test patterns after EUT suppression.

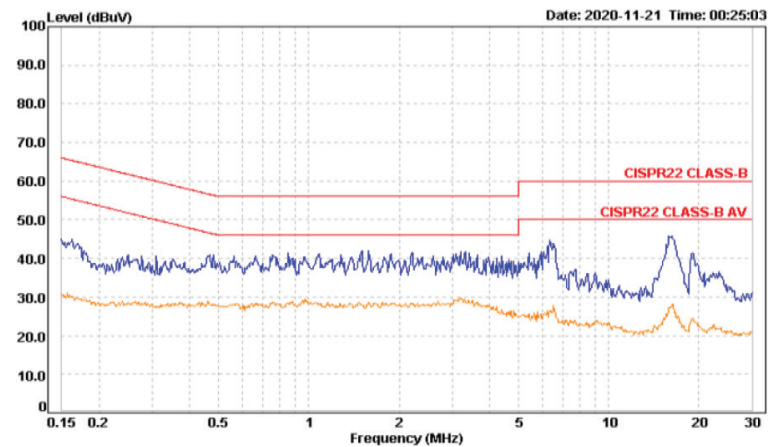

Figure 7 EMI testing of L phase conductivity after the suppression.

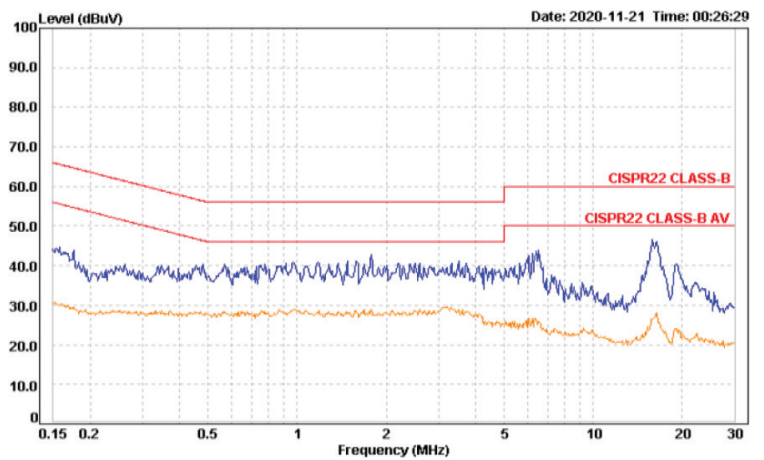

Figure 8 EMI testing of N phase conductivity after the suppression.

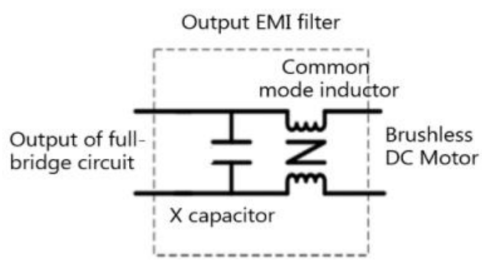

Figure 9 Output EMI filter structure.

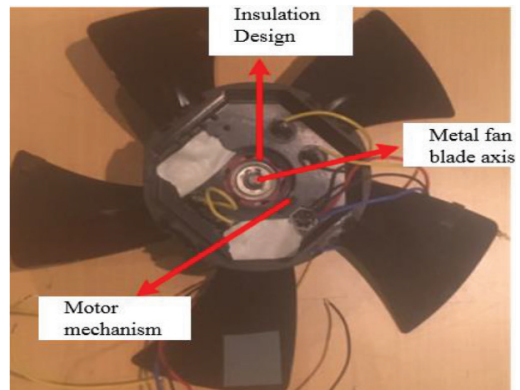

Figure 10 A strategy for motor shaft and mechanism insulation design.

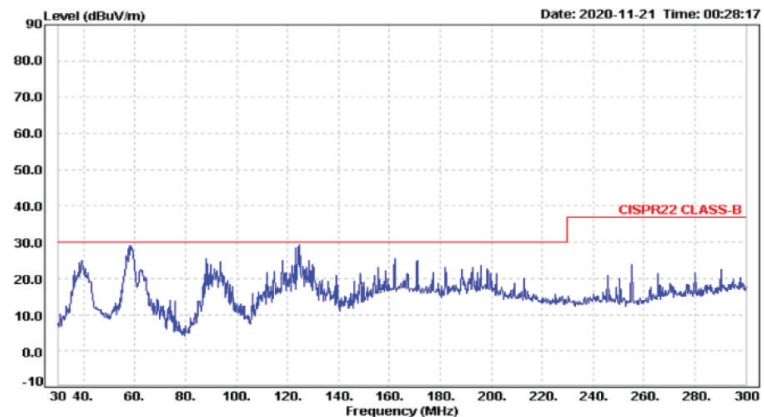

Figure 11 The vertical polarity test of radiation EMI after the suppression.

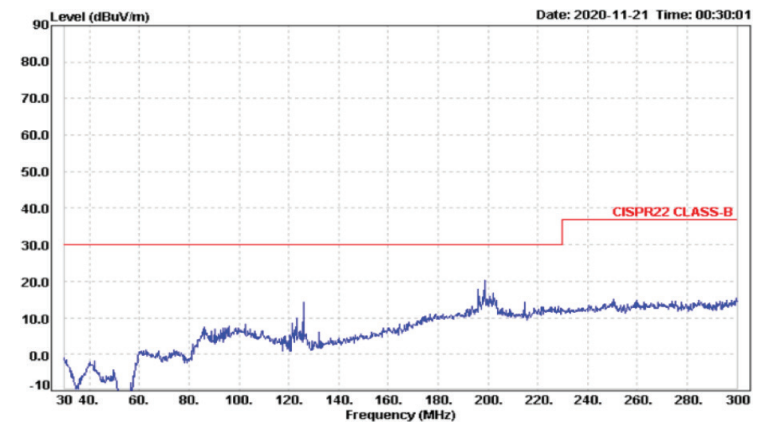

Figure 12 The horizontal polarity test of radiation EMI after the suppression.

\section{CONCLUSION}

This paper has proposed an electronic commutation fan to perform the practical electromagnetic interference certification process for the EUT. The suppression of conductive EMI and radiate EMI was discussed, and a digital control system was designed to reduce the EMI filter components in this research. Meanwhile, the proposed system combines the proper mechanism to solve the problem of serious radiated EMI caused by the system operating without grounding. This method can not only be applied for this product, but also other relative products producing a similar effect. The saving of time and cost will be implemented after a successful certification of the subsequent relative products.

\section{CONFLICTS OF INTEREST}

The authors declare they have no conflicts of interest. 


\section{ACKNOWLEDGMENTS}

The research described in this paper was supported by the Ministry of Science and Technology, the Republic of China (Grant. No. 109-2221-E-150-041-MY3). The authors are indebted to the people at Computer Science and Information Engineering, The National Taiwan University of Science and Technology, for their help in providing the research data of the instrument equipment.

\section{REFERENCES}

[1] S. Chen, T.A. Lipo, D. Fitzgerald, Measurement and analysis of induction motor bearing currents in PWM inverter drives, IEEE Transactions on Industry Applications 32 (1995), 1365-1370.

[2] J. Erdman, R.J. Kerkman, D. Schegel, G. Skibinski, Effect of PWM inverters on AC motor bearing currents and shaft voltages, Proceedings of 1995 IEEE Applied Power Electronics Conference and Exposition - APEC'95, IEEE, Dallas, TX, USA, 1995, pp. 24-33.

[3] H.W. Ott, Noise reduction techniques in electronic Systems, John Wiley \& Sons, New York, 1988.

\section{AUTHORS INTRODUCTION}

\section{Asst. Prof. Ching-Chun Chuang}

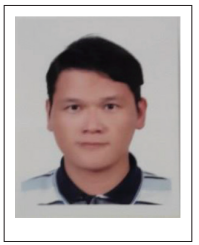

$\mathrm{He}$ received a $\mathrm{PhD}$ degree in Electronics Engineering from the National Taiwan University of Science and Technology, Taiwan, in 2013. Since 2017, he has been an Associate Professor at Computer Science and Information Engineering, Formosa University, Taiwan. His research interests include Power Electronics, Digital Control, IoT Applications, and Robot Applications.

\section{Prof. Chih-Chiang Hua}



He (S'91-M'92) received the B.S. degree in Electrical Engineering from National Cheng Kung University, Tainan, Taiwan, in 1984, and the M.S. and $\mathrm{PhD}$ degrees in Electrical Engineering from the University of Missouri, Columbia, MO, USA, in 1990 and 1992, respectively. Since 1992, he has been with the National Yunlin University of Science and Technology, Douliou, Taiwan, where he is currently a Professor at the Department of Electrical Engineering. His research interests include Power Electronics Converters, Uninterruptible Power Supplies, and Photovoltaic/ Wind Energy Systems. He is a member of the IEEE Power Electronics and the IEEE Industrial Electronics Societies.
[4] C.R. Paul, Introduction to electromagnetic compatibility, John Wiley \& Sons, Hoboken, New Jersey, 1992.

[5] R.L. Ozenbaugh, EMI filter design, Marcel Dekker, New York, 1996.

[6] S. Ogasawara, H. Akagi, Analysis and reduction of EMI conducted by a PWM inverter-fed AC motor drive system having long power cables, 2000 IEEE 31st Power Electronics Specialists Conference, IEEE, Galway, Ireland, 2000, pp. 928-933.

[7] M.L. Heldwein, T. Nussbaumer, F. Beck, J.W. Kolar, Novel threephase CM/DM conducted emissions separator, Twentieth Annual IEEE Applied Power Electronics Conference and Exposition (APEC), IEEE, Austin, TX, USA, 2005, pp. 797-802.

[8] K.B. Hardin, J.T. Fessler, D.R. Bush, A study of the interference potential of spread Spectrum clock generation techniques, Proceedings of International Symposium on Electromagnetic Compatibility, IEEE, Atlanta, GA, USA, 1995, pp. 624-629.

[9] A. Santolaria, J. Balcells, D. Gonzalez, J. Gago, S.D. Gil, EMI reduction in switched power converters by means of spread spectrum modulation techniques, 2004 IEEE 35th Annual Power Electronics Specialists Conference (IEEE Cat. No. 04CH37551), IEEE, Aachen, Germany, 2004, pp. 292-296.

\section{Dr. Chun-Jen Yao}



$\mathrm{He}$ (1980) received a $\mathrm{PhD}$ degree in Electronics Engineering from the National Taiwan University of Science and Technology, Taiwan, in 2010. Since 2017, he has been a Postdoctoral Research Fellow at Electronics Engineering, National Taiwan University of Science and Technology, Taiwan. His research interests include Electromagnetic Compatibility, Power Electronics and Digital Control. 